\title{
Survey on Anxiety in Reading Chinese-English Syntactic Differences: A Case of English Reading Anxiety in Taiwanese University Students
}

\author{
Yu-Hsiu Liu \\ De Lin Institute of Technology, Taipei, Taiwan \\ Email: liu.674@osu.edu \\ Keiko K. Samimy \\ The Ohio State University, Columbus, U.S.A \\ Email: samimy.2@osu.edu
}

\begin{abstract}
This survey study investigated the potential role of Chinese-English syntactic differences in English reading anxiety among 189 Taiwanese university students. With the use of the Foreign Language Reading Anxiety Scale (FLRAS; Saito, Horwitz, \& Garza, 1999) and the Survey of Anxiety in Reading Chinese-English syntactic differences (SARCE; a self-designed measure), the study showed that Chinese-English syntactic differences in the passive and relative constructions were a significant factor attributing to the participants' English reading anxiety.
\end{abstract}

Index Terms - foreign language reading anxiety, Chinese-English syntactic differences, The English relative clause, the English passive, Taiwanese university students

\section{INTRODUCTION}

Foreign language (FL) reading is complex because it is affected by a complex mix of linguistic and nonlinguistic factors inextricably linked together. Among many factors, anxiety has long been found to have a debilitating effect on foreign language reading (e.g., Saito, Horwitz, \& Garza, 1999). A high level of reading anxiety usually distracts language learners' attention from meaning and language forms and may further undermine learners' FL reading development in the long run (Gass \& Selinker, 2001). Despite the tremendous impact of anxiety on FL reading, comparatively little research has been conducted to examine what leads to reading anxiety in the foreign language learning context, particularly in the English as a foreign language (EFL) context in Asia. Hence, this study was conducted to fill a gap in previous research. The primary focus of this study was to examine whether syntactic differences acted as a potential influence on the reading anxiety experienced by Chinese learners of English as a foreign language.

\section{REVIEW OF LITERATURE}

Up to now, relatively few attempts have been made to investigate FL reading anxiety. The most seminal research on FL reading anxiety was conducted by Saito, Horwitz, and Garza (1999). In their study "Foreign Language Reading Anxiety," they employed the Foreign Language Reading Anxiety Scale (FLRAS) to assess American university students' reading anxiety in Japanese, Russian, and French. They found that anxiety had a tremendous impact on students' FL reading and that FL reading anxiety was different in nature from overall FL anxiety. Apart from Saito, Horwitz, and Garza, an increasing number of researchers have attempted to investigate FL reading anxiety in association with other variables, such as assessment methods (Oh, 1992), reading comprehension ability (Brantmeier, 2005; Sellers, 2000), gender (Matsuda \& Gobel, 2004), the use of reading strategies (Zhou, 2008), and so forth. With respect to assessment methods, Oh (1992) used the Cognitive Interference Questionnaire (CIQ) to examine the influence of testing methods on FL reading anxiety. Her study showed that different assessment methods would produce different levels of FL reading anxiety among Korean university students. Regarding the variable of reading comprehension ability, both Sellers (2000) and Brantmeier (2005) utilized the FLRAS to assess FL reading anxiety in American learners of Spanish. It was found that anxious learners tended to have a lower level of reading comprehension ability than did their less-anxious counterparts. In addition to assessment methods and reading comprehension ability, FL reading anxiety has also been studied together with the variables of gender and the use of reading strategies. With respect to gender, Matsuda and Gobel (2004) employed the FLRAS and the FLCAS to measure FL reading anxiety associated with gender. Their study indicated that gender was not a significant predictor of Japanese students' anxiety in reading English as a foreign language. As for the use of reading strategies, Zhou's survey research showed that, in China, anxious EFL readers and less anxious EFL readers differed in their use of reading strategies; that is, highly 
anxious readers were unable to use reading strategies efficiently while processing texts written in English. Overall, previous research has shown that anxiety does not work in isolation to affect FL reading. Multiple factors should also be taken into consideration in the interpretation of FL reading anxiety.

While previous studies have highlighted the significant influence that anxiety can have on FL reading, the scope of most anxiety research is rather limited. Most anxiety research tended to examine FL reading anxiety together with individual differences (e.g., gender, reading comprehension ability, etc.) at the expense of linguistic variables (e.g., syntactic differences, orthography, and so forth). Since FL reading is a complex cognitive process affected by first language (L1) and second language (L2) variables (Koda, 2007), linguistic variables such as syntactic differences should not be overlooked as we examine the influence of anxiety on FL reading. The syntactic differences between two languages are worthy of exploration, especially when we consider reading anxiety in learners whose native language differs tremendously from the FL with respect to syntax (e.g., Cheng, 1993; Cheung, Chan, \& Chong, 2007; Li \& Thompson, 1989).

Comparing English and Chinese for example, since English is an alphabetic language and Chinese is a logographic language, many syntactic differences have been observed to exist between the two languages. For instance, unlike English, which follows a strict word order of subject-verb-object (SVO), a typical Chinese sentence permits both the SVO word order and the SOV word order (Odlin, 1989). In addition, Chinese is a "topic-prominent language", whereas English is a subject-prominent language (Li \& Thompson, 1989, p. 15; Xiao, 2002). These syntactic differences can play a significant role in the way Chinese learners read English (Chen, 2005; Green, 1996; Yip \& Matthews, 2000). Many studies have shown that Chinese students' English reading problems and production errors usually result from syntactic interference (e.g., Odlin, 1989) and from students' lack of awareness of Chinese-English syntactic differences (Chan, 2004a, 2004b; Cheng, 1993). In this sense, Chinese-English syntactic differences may be a crucial factor to consider as we investigate the role of anxiety in Chinese speakers' English reading. Unfortunately, it appears that no research has ever been conducted to examine how Chinese-English syntactic differences shape English reading anxiety in Chinese students.

Considering the limitations of previous research, the present study aimed to investigate the interplay between syntactic differences and FL reading anxiety among Asian students, a less examined population in anxiety research. Specifically, this study employed the FLRAS (Saito et al., 1999) and a newly designed instrument, "The Survey on Anxiety in Reading Chinese-English Syntactic Differences" (SARCE) to examine how Taiwanese university students perceived the role of Chinese-English syntactic differences in their English reading anxiety.

\section{RESEARCH QUESTIONS}

Three research questions were posed to investigate the role of Chinese-English syntactic differences in Taiwanese university students' perceptions of English reading anxiety:

1. To what extent do Taiwanese university students experience anxiety in reading English?

2. What are the underlying common factors behind Taiwanese university students' English reading anxiety associated with Chinese-English syntactic differences?

3. What role do Chinese-English syntactic differences play in Taiwanese university students' English reading anxiety?

\section{Methodology}

\section{A. Participants}

The participants in this study consisted of 189 Taiwanese university students from assorted majors at a university in Northern Taiwan. A total of 250 questionnaires were distributed to accessible participants, and 213 questionnaires were returned. The response rate was $85 \%$. Of the 213 questionnaires, 24 were incomplete and were eliminated. Hence, the selected sample of this study was 189 students, consisting of 85 males (45\%) and 104 females (55\%).

\section{B. Procedure}

The participants were asked to respond to the FLRAS first, to read two assigned articles (i.e., Article A and Article B) next, and to respond to the SARCE last.

\section{Instruments and Materials}

\section{The Foreign Language Reading Anxiety Scale (FLRAS)}

Developed by Saito, Horwitz, and Garza (1999), the FLRAS has been viewed as a highly valid and reliable instrument to measure foreign language reading anxiety (Gonen, 2007; Matsumura, 2001; Miyanaga, 2005; Saito et al., 1999). The FLRAS is a 20-item questionnaire based on a five point summated Likert-type scale. The response categories range from strongly disagree to strongly agree and inquire about 'students' self-reports of anxiety over various aspects of reading, their perceptions of reading difficulties in their target language, and their perceptions of the relative difficulty of reading as compared to the difficulty of other language skills" (Saito et al., 1999, p. 204). Since the FLRAS was developed to measure non-Asian students' FL reading anxiety in the U.S. context, the original FLRAS was adapted to meet the needs of the present study. The only difference between the adapted FLRAS and the original 
FLRAS is the wording. Despite that, the adapted FLRAS retains the same number, content, and ordering of the items on the original FLRAS.

\section{Texts With and Without Chinese-English Syntactic Differences}

Two articles, Article A ("Alice") and Article B ("Marianne") were used to examine whether the amounts of ChineseEnglish syntactic differences have a potential influence on the participants' levels of English reading anxiety (please view Appendix A). Drawn from two reading sections of the Practice Test of English as a Foreign Language (TOEFL), the two articles (each containing 223 words) are relevant because both discuss the life and work of a famous American writer, with Article A being about Alice Walker, and Article B being about Marianne Moore. Despite these similarities, the two articles differ in the amounts of Chinese-English syntactic differences that they contain. Article A is written using the subject-verb-object (SVO) order, which resembles the Chinese word order, while Article B contains a large number of passive sentences and relative constructions (13 out of 15 sentences (87\%) are either passivized or relativized), which is uncommon in a typical Chinese article. In other words, Article A contains neither passive sentences nor relative constructions, whereas Article B includes a great number of the two constructions. More ChineseEnglish syntactic differences are found in Article B than in Article A.

3. The Survey on Anxiety in Reading Chinese-English Syntactic Differences (SARCE)

As a measure of participants' post-reading anxiety deriving from a text containing large Chinese-English syntactic differences (i.e., Article B), the SARCE contains 20 survey items on a four point Likert-type scale, with response categories of strongly disagree, disagree, agree, and strongly agree. Based on previous research findings that Chinese students' English reading problems originate primarily from syntactic differences between the Chinese relative and the English relative constructions, and between the Chinese passive and the English passive voice (e.g., Odlin, 1989), the original survey items were grouped into four domains, with 4 items on awareness of syntactic differences between the assigned texts (i.e., Article A and Article B), 5 items on the English relative construction, 5 items on the English passive, and 6 items on overall feelings of anxiety in reading the assigned texts.

The SARCE was pilot-tested with 15 Taiwanese university students to ensure its reliability before group administration. Prior to pilot testing the SARCE, five Taiwanese university students were invited to participate in cognitive interviews to ensure clarity and appropriateness of the survey items. The internal consistency of the 20 items on the SARCE was tested by Cronbach's alpha. The reliability results of the pilot test showed that the Cronbach's alpha for items in the first domain was .78; the Cronbach's alpha for items in the second domain was .83; the Cronbach's alpha for items in the third domain was .79; and the Cronbach's alpha for items in the fourth domain was .74. In addition, content validity and face validity of the SARCE were also established by two ESL teachers and a panel of three experts who specialized in second language acquisition, second language reading, and survey research.

\section{DATa ANALYSIS}

The Statistical Package for the Social Science (SPSS), version 18.0 was used to analyze the survey data. The analyses consisted of the use of descriptive statistics (e.g., means, standard deviations, percentages, frequencies, etc.), a Pearson product-moment correlation coefficient analysis, and an exploratory factor analysis.

\section{RESULTS AND DiSCUSSION}

\section{A. Levels of Reading Anxiety in English}

The Cronbach's alpha of the modified FLRAS was .81 $(\mathrm{n}=189)$, showing that the slightly modified FLRAS was a reliable instrument for use in this study. The mean FLRAS score of the participants was $65.8(S D=10.06)$.

Measured by the FLRAS scores, the participants' levels of English reading anxiety were compared using the principles suggested by Sellers (2000) and Gonen (2007). Accordingly, the high-anxiety group included individuals whose mean scores were one or more standard deviations above the total mean; the low-anxiety group contained those whose mean scores were one or more standard deviations below the total mean; and the remainder of the participants were in the mid-anxiety group. The table below shows the frequency distribution of the three groups:

TABLE 1

\begin{tabular}{lllll}
\multicolumn{5}{c}{ DISTRIBUTION OF THE HIGH-, MID-, AND LOW-ANXIETY GROUPS ON THE FLRAS } \\
\hline Group & $\mathbf{N}$ & $\mathbf{\%}$ & Mean & SD \\
\hline High-anxiety $^{\mathrm{a}}$ & 25 & 13.2 & 82.76 & 4.23 \\
Mid-anxiety $^{\mathrm{b}}$ & 133 & 70.4 & 67.64 & 5.23 \\
Low-anxiety $^{\mathrm{c}}$ & 31 & 16.4 & 50.84 & 4.56 \\
Total & 189 & 100.0 & & \\
\hline \multicolumn{5}{c}{ Note. a. High-anxiety group: Individuals whose FLRAS scores > 77 (total M of the FLRAS+ 1SD) } \\
b. Mid-anxiety group: Individuals whose FLRAS scores: 57-77 \\
\multicolumn{5}{c}{ c. Low-anxiety group: Individuals whose FLRAS scores < 57 (total M of the FLRAS - 1SD) }
\end{tabular}

As shown in Table 1, the high-anxiety group has the highest mean score of $82.76(S D=4.23)$ on the FLRAS among the groups. The mid-anxiety group consisted of the largest number of participants $(n=133,70.4 \%)$, followed by the low-anxiety group $(\mathrm{n}=31,16.4 \%)$. Table 1 also shows that the numbers of the participants in the high-and low-anxiety 
groups were very close, with a 3.2 percentage points difference between the two groups. Despite the low-anxiety group, the majority of participants $(83.6 \%)$ reported that they had experienced anxiety while reading English.

A closer look at the participants' FLRAS scores shows that the total means and standard deviations of the FLRAS scores of the current study are much higher than those reported by Gonen (2007), Huang (2001), and Saito et al. (1999). This finding indicates that the participants in this study experienced higher levels of reading anxiety than did participants recruited in previous research. The fact that the participants had higher reading anxiety also corresponds to the observed group composition, in which $13.2 \%$ of the participants were placed in the high-anxiety group, $70.4 \%$ in the mid-anxiety group, and $16.4 \%$ in the low-anxiety group. In other words, approximately $83.6 \%$ of the participants experienced mid- to high levels of reading anxiety.

The aforementioned findings confirm the existing anxiety research, demonstrating that FL reading is anxietyprovoking for language learners (e.g., Gonen, 2007; Saito et al., 1999; Sellers, 2000; Zhou, 2008). Furthermore, the findings also support recent studies conducted by Hou (2008), Hsiao (2002), Hsu (2004), and Huang (2001) by showing that English reading anxiety is an overarching problem facing most Taiwanese students.

\section{B. Results of the SARCE}

Table 2 presents the means and standard deviations of the 20 items on the SARCE. The largest mean value was 2.91 (item 18), whereas the smallest was 2.24 (item 11). The mean differences of the items were very small, varying less than one point from the total mean of $2.63(N=189, S D=.76)$. A closer examination of the items with means higher than the total mean (i.e., items 16, 18, 19, 20) shows that the participants were more anxious when reading a text containing large Chinese-English syntactic differences (i.e., Article B).

TABLE 2

MEANS AND STANDARD DEVIATIONS OF TWENTY ITEMS ON THE SARCE

\begin{tabular}{llll}
\hline Item & Mean & SD & N \\
\hline 1. Confusion about reading Article B that contains many English RCs & 2.50 & .719 & 189 \\
2. Unfamiliarity with Chinese-English differences in the passive voice & 2.54 & .768 & 189 \\
3. Syntactic differences between Article A and a typical Chinese article & 2.83 & .663 & 189 \\
4. Syntactical differences and reading comprehension & 2.76 & .701 & 189 \\
5. Familiarity with the English RC & 2.59 & .742 & 189 \\
6. Problem of reading the English RC & 2.40 & .704 & 189 \\
7. Difficulty in analyzing the English RC & 2.72 & .698 & 189 \\
8. General anxiety in reading the English RC & 2.32 & .703 & 189 \\
9. Anxiety in reading Article B that contains many English RCs & 2.48 & .726 & 189 \\
10. Familiarity with English passives & 2.39 & .725 & 189 \\
11. Problem of reading English passives & 2.24 & .747 & 189 \\
12. Difficulty in analyzing English passives & 2.54 & .788 & 189 \\
13. General anxiety in reading English passives & 2.26 & .701 & 189 \\
14. Anxiety in reading Article B that contains many English passives & 2.36 & .720 & 189 \\
15. Feeling of depression due to poor comprehension of Article B & 2.58 & .826 & 189 \\
16. Anxiety in having Article B as a reading test & 2.81 & .711 & 189 \\
17. Anxiety in reading Article B at leisure & 2.59 & .729 & 189 \\
18. Chinese-English syntactic differences and English reading anxiety & 2.91 & .770 & 189 \\
19. Discomfort in reading texts with large syntactic differences & 2.78 & .832 & 189 \\
20. Confidence in reading Article B & 2.80 & .728 & 189 \\
\hline
\end{tabular}

\section{The Underlying Structure of the SARCE}

To examine the underlying structure of the SARCE, an exploratory factor analysis using principal components analysis with varimax rotation was performed on 20 items of the SARCE for the 189 participants. The KMO value of .87 and the Barlett's test of sphericity $(p=.00)$ showed appropriateness of using the factor analysis on the data.

An examination of a scree plot shows that three components with eigenvalues greater than one were extracted: (1) the English passive, (2) anxiety in reading a text containing large syntactic differences, and (3) the English relative clause. Together the three components explained $50.4 \%$ of the total variance of the participants' English reading anxiety associated with Chinese-English syntactic differences. The results of the analysis are summarized in Table 3 below. 
TABLE 3

RESULTS OF THE EXPLORATORY FACTOR ANALYSIS FOR THE SARCE

\begin{tabular}{|c|c|c|c|c|c|}
\hline Component & Loading & Communality & Eigenvalue & $\begin{array}{l}\text { Percent of } \\
\text { Variance } \\
\text { Explained }\end{array}$ & $\begin{array}{l}\text { Cumulative } \\
\text { Percent of } \\
\text { Variance } \\
\text { Explained } \\
\end{array}$ \\
\hline The English Passive (alpha= .876) & & & 4.413 & $22.065 \%$ & $22.065 \%$ \\
\hline Item 13 & .841 & .806 & & & \\
\hline Item 11 & .822 & .773 & & & \\
\hline Item 12 & .778 & .681 & & & \\
\hline Item 14 & .761 & .742 & & & \\
\hline Item 10 & .599 & .535 & & & \\
\hline Item 2 & .568 & .612 & & & \\
\hline $\begin{array}{l}\text { Anxiety in Reading a Text Containing Large } \\
\text { Syntactic Differences }(\text { alpha }=.821)\end{array}$ & & & 3.003 & $15.013 \%$ & $37.078 \%$ \\
\hline Item 16 & .814 & .747 & & & \\
\hline Item 17 & .797 & .731 & & & \\
\hline Item 20 & .764 & 699 & & & \\
\hline Item 15 & .643 & .580 & & & \\
\hline The English Relative Clause (alpha=.725) & & & 2.656 & $13.28 \%$ & $50.358 \%$ \\
\hline Item 7 & .712 & .598 & & & \\
\hline Item 5 & .687 & .587 & & & \\
\hline Item 1 & .683 & .646 & & & \\
\hline Item 9 & .487 & .550 & & & \\
\hline
\end{tabular}

As shown in Table 3, the first rotated component, with $22.07 \%$ of the variance explained, consisted of six items (2, 10-14): \#2, Unfamiliar with the differences between Chinese passives and English passives, I am not sure if I interpret Article B correctly; \#10. I am familiar with the English passive; \#11, I usually get stuck in my reading of English when I encounter English passives; \#12, I sometimes have difficulty in processing English passives; \#13, I am anxious whenever I come across passive sentences in my reading of English; and \#14, I feel anxious reading Article B because there are many passive sentences in Article B. Since the items concerned the participants' feelings of anxiety and learning difficulties with the English passive, the first component was named "the English passive."

The second rotated component, with approximately $15.01 \%$ of the variance explained, contained four items, including \#15, I am frustrated because I cannot comprehend Article B very well; \#16, I would be more anxious if I were given Article B, rather than Article A, to read in an exam; \#17, I would be more anxious if I were given Article B, rather than Article A, to read in my free time; and \#20, I feel less confident when reading Article B. Given that the above items described the participants' overall reaction after reading a text containing large Chinese-syntactic differences (i.e., Article B), the second component was named "anxiety in reading a text containing large syntactic differences."

The third rotated component, with $13.28 \%$ of the variance explained, comprised four items, such as \#1, Because Chinese has no relative clauses, I feel confused when reading Article B that contains many relative clauses; \#5, I am familiar with the English relative construction; \#7, I sometimes have difficulty in processing sentences containing relative clauses; and \#9, I feel anxious reading Article B because there are many relative clauses in Article $B$. The third component was labeled "the English relative clause" in that the items loaded on the third component were relevant to the participants' feelings of anxiety and learning difficulties with the English relative clause.

The extracted components the English passive and the English relative clause echo previous research findings that syntactic differences between Chinese and English, particularly the relative and the passive constructions, can interfere with Chinese students' English as a second or foreign language reading (Chan, 2004a, 2004b; Cheng, 1993; Odlin, 1989). Chinese-English syntactic differences associated with the relative and passive constructions should thus be considered a potential factor in explaining Chinese students' reading of English. The findings of this study also add insight to the existing research by showing that Chinese-English syntactic differences may not only lead to English reading problems but also shape the way Chinese students perceive English reading anxiety, as identified by the second extracted component (i.e., anxiety in reading a text containing large syntactic differences).

\section{The Relationship between the FLRAS and the SARCE}

The descriptive results of the SARCE showed that the majority of participants (78\%) agreed that Chinese-English syntactic differences are an important factor that causes English reading anxiety. In addition, the Pearson correlation coefficient, .647, showed that there was a moderate, positive relationship between the FLRAS and the SARCE $(p=.00)$ The proportion of variability shared by the FLRAS and the SARCE was $41.86 \%$. The correlation analysis showed that the participants who received high scores on the FLRAS tended to score highly on the SARCE, and vice versa. These results showed that English reading anxiety is related to, but distinct from, reading anxiety arising from ChineseEnglish syntactic differences.

\section{CONCLUSION, IMPLICATIONS, AND RECOMMENDATIONS}

This study was conducted in an attempt to explore the link between Chinese-English syntactic differences and Taiwanese university students' English reading anxiety. The overall results of the study showed that Chinese-English 
syntactic differences played a crucial role in shaping the participants' English reading anxiety. In addition, the participants experienced a mid-to-high level of English reading anxiety and their English reading anxiety could be explained by three underlying common factors: the English passive, the English relative clause, and an authentic text containing gross Chinese-English syntactic differences. Using psychological and linguistic perspectives, this study is also important in that it shows that FL reading anxiety is subject to the influence of syntactic differences, especially between an alphabetic language such as English and a non-alphabetic language such as Chinese.

Two implications for English as a foreign language (EFL) reading instruction can be derived from the results of this study. First, in view of the result that the participants experienced overall anxiety in reading English, there is a need for English reading teachers to create a low-anxiety reading environment for EFL learners. Teachers should be aware that the process of FL reading is impacted by cognitive, social, and psychological factors. Diagnosing why students are unable to read well is as important as teaching them how to read well. Since acute reading anxiety can impair students' long-term development of reading skills in the L2/FL, reducing students' reading anxiety is of great importance in English reading classrooms. Second, considering the important role of Chinese-English syntactic differences in English reading anxiety, reading teachers should bear in mind that gross Chinese-English syntactic differences in the relative and passive constructions could be a potential source of English reading anxiety for Chinese learners of English. Teachers should help students build an awareness of how Chinese and English differ in word order. Specifically, as suggested by Sun and Cong (2005) and Tsao (1986), teachers may consider doing an error analysis and a contrastive analysis of the Chinese passive/relative clause and the English passive/relative clause for their students. In so doing, students can become more familiar with the English passive and the English relative clause and thus suffer less from reading anxiety and difficulties caused by the two constructions.

Future research should investigate more deeply the question of whether syntactic differences between an alphabetic language and a non-alphabetic language or among languages of the same writing system have a long-term impact on the formation of FL reading anxiety. Apart from the survey technique, researchers may consider using the qualitative research paradigm to better investigate the influence of syntactic differences on foreign language reading anxiety. After all, reading anxiety is a multidimensional construct that needs to be further defined using more than a single research paradigm.

\section{APPENDIX A READING MATERIALS}

\section{Article A: Alice}

Alice Walker makes her living by writing, and her poems, short stories, and novels have won many awards and fellowships for her. She was born in Eatonton, Georgia. She went to public schools there, and then to Spelman College in Atlanta before coming to New York to attend Sarah Lawrence College. She graduated from Sarah Lawrence College in 1966. For a time she lived in Jackson, Mississippi, with her lawyer husband and small daughter. About Langston Hughes, American Poet, her first book for children, she says, "After my first meeting with Langston Hughes I vowed I would write a book about him for children someday. Why? Because I, at twenty-two, knew next to nothing of his work, and he didn't scold me; he just gave me a stack of his books. And he was kind to me; I will always be grateful that in his absolute warmth and generosity, he fulfilled my deepest dream (and need) of what a poet should be."

"To me he is not dead at all. Hardly a day goes by that I don't think of him or speak of him. Once, just before he died, when he was sick with the flue, I took him a sack full of oranges." She said she still remembered how happy she was when Langston Hughes said he liked oranges, too.

\section{Article B: Marianne}

Marianne Moore once said that her writing could be called poetry only because there was no other name for it. Indeed her poems appear to be extremely compressed essays that happen to be printed in jagged lines on the page. Her subjects were varied: animals, laborers, artists, and the craft of poetry. From her general reading came quotations that she found striking or insightful. She included these in her poems, scrupulously enclosed in quotation marks, and sometimes identified in footnotes. Of this practice, she wrote, “'Why the many quotation marks?' I am asked...When a thing has been said so well that it cold not be said better, why paraphrase it? Hence my writing is, if not a cabinet of fossils, a kind of collection of flies in amber."

Her first book of poems was published in London in 1921 by a group of friends associated with the Imagist movement. From that time on her poetry has been read with interest by succeeding generations of poets and readers. In 1952 she was awarded the Pulitzer Prize for her Collected Poems. She wrote that she did not write poetry "for money or fame. To earn a living is needful, but it can be done in routine ways. One writes because one has a burning desire to objectify what it is indispensable to one's happiness to express..."

\section{REFERENCES}

[1] Brantmeier, C. (2005). Anxiety about L2 reading or L2 reading tasks? A study with advanced language learners. The Reading Matrix, 5(2), 67-83. 
[2] Chan, A. Y. W. (2004a). Noun phrases in Chinese and English: A study of English structural problems encountered by Chinese ESL students in Hong Kong. Language, Culture \& Curriculum, 17(1), 33-47.

[3] Chan, A. Y. W. (2004b). Syntactic transfer: Evidence from the interlanguage of Hong Kong Chinese ESL learners. The Modern Language Journal, 88(1), 56-74.

[4] Chen, M. Y. C. (2005). English prototyped small clauses in the interlanguage of Chinese/Taiwanese adult learners. Second Language Research, 21(1), 1-33.

[5] Cheng, T. Y. (1993). The syntactical problems Chinese college students meet in reading English technical textbooks. Retrieved May 17, 2009, from ERIC: http://web.ebscohost.com/ehost/detail?vid=7\&hid=113\&sid=b0ebec5d-93bf-419a-bbe08c02df5b9947\%40sessionmgr102

[6] Cheung, H., Chan, M., \& Chong, K. (2007). Use of orthographic knowledge in reading by Chinese-English bi-scriptal Children. Language Learning, 57(3), 469-505.

[7] Educational Testing Services. (1998).TOEFL test preparation kit: Workbook. Princeton: Educational Testing Services.

[8] Gass, S. M., \& Selinker, L. (2001). Second language acquisition: An introductory course. Mahwah: Lawrence Erlbaum Associates.

[9] Gonen, S. I. K. (2007). L2 reading anxiety: Exploring the phenomenon. Paper presented in JALT conference, Retrieved December 28, 2009 from http://jalt-publications.org/archive/proceedings/2006/E082.pdf

[10] Green, C. (1996). The origins and effects of topic-prominence in Chinese-English interlanguage. IRAL: International Review of Applied Linguistics in Language Teaching, 34(2), 119-135.

[11] Hou, T. C. (2008). The relationship between English reading anxiety and English reading comprehension among EFL nonEnglish majors in a vocational high school. Unpublished master's thesis, Chaoyang University of Technology, Taichchung, Taiwan.

[12] Hsiao, T. Y. (2002). Unidimensionality of the Chinese version of the foreign language reading anxiety scale. Perceptual and Motor Skills, 95, 927-933.

[13] Hsu, Y. C. (2004). A study on junior college students' reading anxiety in English as a foreign language. Unpublished master's thesis, National Chung Cheng University, Chiayi, Taiwan.

[14] Huang, H. Y. (2001). Chinese university foreign language students' anxiety about reading in English. Unpublished doctoral dissertation, Washington State University, Washington, The United States.

[15] Koda, K. (2007). Reading and language learning: Crosslinguistic constraints on second language reading development. Language Learning, 57, 1-44.

[16] Li, C. N., \& Thompson, S. (1989). Mandarin Chinese: A functional reference grammar. Berkeley: University of California Press, Ltd.

[17] Matsuda, S., \& Gobel, P. (2004). Anxiety and predictors of performance in the foreign language classroom. System, 32(1), 2137.

[18] Matsumura, Y. (2001). An inquiry into foreign language reading anxiety among Japanese EFL learners. The Society of English Studies, 31, 23-38.

[19] Miyanaga, C. (2005). How reliable and valid is the adapted version of the foreign language reading anxiety scale (FLRAS) for Japanese university students? Language and Culture, 4, 1-17.

[20] Odlin, T. (1989). Syntax. In Language Transfer (pp.85-110). New York: Cambridge University Press.

[21] Oh, J. (1992). The effects of L2 reading assessment methods on anxiety level. TESOL Quarterly, 26(1), 172-176.

[22] Saito, Y., Horwitz, E. K., \& Garza, T. J. (1999). Foreign language reading anxiety. The Modern Language Journal, 83(2), 202218.

[23] Sellers, V. (2000). Anxiety and reading comprehension in Spanish as a foreign language. Foreign Language Annals, 33(5), $512-521$.

[24] Sun, Y. J. \& Cong, Y. X. (2005). The study of nominalization acquisition in Chinese EFL learners. China English Language Education Association Journal, 28(6), 89-94.

[25] Tsao, F. F. (1986). Relativization in Chinese and English: A contrastive study of form and function. Journal of the Chinese Language Teachers Association, 21, 13-47.

[26] Xiao, Y. (2002). The syntactic development of school-age Chinese-speaking children learning English. IRAL: International Review of Applied Linguistics in Language Teaching, 40(3), 235-271.

[27] Yip, V., \& Matthews, S. (2000). Syntactic transfer in a Cantonese-English bilingual child. Bilingualism: Language and Cognition, 3(3), 193-208.

[28] Zhou, S. M. (2008). Study on the relationship between the reading anxiety and the reading strategy in foreign language learning. Sino-US English Teaching, 5(3), 28-34.

Yu-Hsiu Liu received her Ph.D. in foreign, second, and multilingual language education from the School of Teaching and Learning, College of Education and Human Ecology at The Ohio State University, Columbus, Ohio, U.S.A, in 2011. She obtained her masters' degree in TESOL from the Graduate School of Education at the University of Pennsylvania, U.S.A. She is now an assistant professor at De Lin Institute of Technology in Taiwan.

Keiko K. Samimy received her Ph.D. in second language acquisition and teaching from the University of Illinois, UrbanaChampaign. Currently, she is a professor in foreign, second, and multilingual language education at The Ohio State University. 